\title{
Simultaneous Measurement of Temperature and Refractive Index Based on An SPR Silicon Core Fiber Sensor with a Fused Silica Grating Design
}

\author{
Yi Lin Yu ( $\nabla$ ylyu@fcu.edu.tw ) \\ Feng Chia University \\ Hiroki Kishikawa \\ Tokushima University \\ Shien-Kuei Liaw \\ National Taiwan University of Science and Technology \\ Nobuo Goto
}

Tokushima University

Wen-Fung Liu

Feng Chia University

\section{Research Article}

Keywords: Fiber sensor, Silicon core fiber, Surface plasmon resonance, Finite element method (FEM)

Posted Date: November 2nd, 2021

DOl: https://doi.org/10.21203/rs.3.rs-968903/v1

License: (9) This work is licensed under a Creative Commons Attribution 4.0 International License. Read Full License

Version of Record: A version of this preprint was published at Optical and Quantum Electronics on January 1st, 2022. See the published version at https://doi.org/10.1007/s11082-021-03430-9. 


\title{
Simultaneous Measurement of Temperature and Refractive Index Based on An SPR Silicon Core Fiber Sensor with a Fused Silica Grating Design
}

\author{
Yi-Lin Yu ${ }^{1, *}$, Hiroki Kishikawa², Shien-Kuei Liaw ${ }^{3}$, Nobuo Goto ${ }^{2}$, and Wen-Fung Liu ${ }^{1}$. \\ ${ }^{I}$ Department of Electrical Engineering, Feng-Chia University, Taichung, 40724, Taiwan (R.O.C.) \\ ${ }^{2}$ Department of Optical Science, Tokushima University, Tokushima, 770-8506, Japan \\ ${ }^{3}$ Department of Electronic and Computer Engineering, National Taiwan University of Science and \\ Technology, Taipei, 10607, Taiwan (R.O.C.) \\ *ylyu@fcu.edu.tw
}

\begin{abstract}
This paper proposed a fiber sensor based on a Silicon core fiber incorporated with a fused silica grating design. The proposed structure is a nice sensitive in refractive index and temperature variation through theoretical calculation and finite element method simulation. The sensitivities of the refractive index in different polarization directions are 1838.7 and $1949.8 \mathrm{~nm} / \mathrm{RIU}$, respectively, within the index range from 1.28 to $1.38 \mathrm{RIU}$. The temperature range within 15 to $40{ }^{\circ} \mathrm{C}$ has the sensitivity up to $1.6 \mathrm{~nm} /{ }^{\circ} \mathrm{C}$ by using ethanol analyte. The proposed fiber sensor can provide a method or a solution for intelligent sensing systems.
\end{abstract}

Keywords Fiber sensor, Silicon core fiber, Surface plasmon resonance, Finite element method (FEM)

\section{Introduction}

The sensing application based on the elements of optical fibers has many advantages including the high sensitivity, miniaturization, electromagnetic wave immunity, real-time and remote sensing capability [1-2]. In these decades, the most popular fiber sensing device included fiber Bragg gratings (FBGs) [3] and long-period fiber gratings (LPFGs) [4] because they were stable and the mature fabricated methods. However, the sensitivity of refractive index (RI) and temperature with fiber gratings were lower than others novel technologies because of intrinsic fiber structure and materials as well as detection mechanisms. Currently one popular fiber sensor consisted of a fiber-based interferometer. There were various types of fiber-based interferometer, such as Mach-Zehnder interferometers (MZI) [5], Michelson interferometers (MI) [6], Fabry-Perot interferometers (FPI) [7], Sagnac interferometers (SI) [8], and multiple modes interferometers (MMI) [9]. Moreover, their sensitivities can be improved via the loss of novel designs owning to their various structures. The primary mechanism of our proposed sensing method is based on the surface plasmon resonance (SPR) [10] in which the surface plasmon polaritons (SPPs) to be excited are electromagnetic waves propagating at the interface between the dielectric and metal layers. In these years, the SPR based refractive index fiber sensor becomes more attractive because of its ultra-high sensitivity than most popular fiber sensors [11-12]. C. Liu et al. [13] proposed an SPR 
sensor based on photonic crystal fiber with indium tin oxide film, and the performance of refractive index sensitivity was ultra-high up to $35000 \mathrm{~nm} / \mathrm{RIU}$ for the analyte range between 1.26 and 1.38 . We have demonstrated an SPR sensor incorporated with silicon core fiber with a more comprehensive RI sensing range from 1.25 to 1.6 , and the operating wavelength band could extend to $2 \mu \mathrm{m}$ [14]. In addition, the SPR based sensor also could be applied for temperature sensing by using a liquid-filled hollow-core negative-curvature fiber, and the temperature sensitivity was $2.86 \mathrm{~nm} /{ }^{\circ} \mathrm{C}$ in the range of $20-40{ }^{\circ} \mathrm{C}$ [15]. However, it is necessary to detect the refractive index with temperature simultaneously because of the RI of material changes with the response to temperature variation. For example, the RI of ethanol in 20 and $25^{\circ} \mathrm{C}$ were 1.364769 and 1.362852 , respectively [16]. There is a relationship parameter between the temperature and refractive index to be called as a thermo-optics coefficient (TOC) [17]. Therefore, the RI measurement without considering the thermal effect may cause the analyte to be misjudged. In 2017 , we proposed a complex sensor combined with an FBG and LFPG for RI and temperature detection [18]. However, the sensitivity of RI and temperature were only $36.808 \mathrm{~nm} / \mathrm{RIU}$ and $0.3472 \mathrm{~nm} /{ }^{\circ} \mathrm{C}$, respectively. Y. Zhang et al. [19] proposed a sensor based on a hybrid SPR multimode interference fiber sensor with the RI sensitivity of $2061.6 \mathrm{~nm} / \mathrm{RIU}$ and temperature sensitivity of $0.038 \mathrm{~nm} /{ }^{\circ} \mathrm{C}$.

In this paper, we theoretically analyzed the performance of an SPR sensor that could detect and analyze both the RI and temperature for an unknown liquid. Our design was based on a silicon core fiber incorporated with a fused silica grating, and the sensitivity of our proposed sensor in RI sensing could reach to $1838.7 \mathrm{~nm} / \mathrm{RIU}$ and $1949.8 \mathrm{~nm} / \mathrm{RIU}$ for different polarization directions in the range between 1.28 to 1.38 . The temperature sensitivity of $1.6 \mathrm{~nm} /{ }^{\circ} \mathrm{C}$ is obtained in the range from 15 to $40{ }^{\circ} \mathrm{C}$, respectively regarding to the effect of the structure thermal expansion and TOC for the ethanol analyte. It is higher than that of previous publications [20-21], which is contributed to the higher thermal expansion and TOC of silicon material used as transmission core. A detailed description of the sensor design and numerical modeling analysis are given in the next section, followed by an interpretation of the influences of several structural variables on the sensor performance.

\section{Model Design and Analysis}

Figure 1(a) illustrates the cross-sectional view of the proposed grating-assisted surface plasmon resonance sensor, which is designed by a silicon core fiber. The radii both of the silicon core and fused silica cladding of the proposed SCF sensor in the original setting is $0.5 \mu \mathrm{m}\left(\mathrm{r}_{\mathrm{c}}\right)$ and $5 \mu \mathrm{m}\left(\mathrm{r}_{\mathrm{cl}}\right)$, respectively. The refractive index of the silicon and fused silica can be obtained by Sellmeier equation as shown in Eq. (1) and (2), respectively, which can be express as [22]:

$$
n^{2}(\lambda)-1=\frac{10.6684293 \cdot \lambda^{2}}{\lambda^{2}-0.301516485^{2}}+\frac{0.0030434748 \cdot \lambda^{2}}{\lambda^{2}-1.13475115^{2}}+\frac{1.54133408 \cdot \lambda^{2}}{\lambda^{2}-1104^{2}}
$$

and [15]

$$
n^{2}(\lambda, T)=\left(1.31552+6.90754 \times 10^{-6} \cdot T\right)+\frac{\left(0.788404+23.5835 \times 10^{-6} \cdot T\right) \lambda^{2}}{\lambda^{2}-\left(0.0110199+0.584758 \times 10^{-6} \cdot T\right)}+\frac{\left(0.91316+0.548368 \times 10^{-6} \cdot T\right) \lambda^{2}}{\lambda^{2}-100}
$$

Here, $\mathrm{T}$ is the temperature in ${ }^{\circ} \mathrm{C}$, and $\lambda$ is the free-space wavelength in $\mu \mathrm{m}$. In addition, the gold film is 
used as the dielectric interference for SPR, and the dielectric constant $\varepsilon$ of gold can be described by the Drude model and written as follows [23]:

$$
\varepsilon(\omega)=\varepsilon_{1}+\mathrm{i} \varepsilon_{2}=\varepsilon_{\infty}-\frac{\omega_{\mathrm{p}}^{2}}{\omega\left(\omega+\mathrm{i} \omega_{\mathrm{c}}\right)}
$$

where $\omega_{\mathrm{c}}$ is the collision frequency, $\omega_{\mathrm{p}}$ is the plasma frequency, and $\varepsilon_{\infty}$ is the absorption peaks at high frequency $\left(\omega \gg \omega_{c}\right)$. In our simulation case with gold, the parameters $\omega_{c}, \omega_{\mathrm{p}}$ and $\varepsilon_{\infty}$ were $1.45 \times 10^{14} \mathrm{~Hz}$, $1.3659 \times 10^{16} \mathrm{~Hz}$ and 9.75 , respectively, which were fitted well into the experimental data in ref. [24]. The plasma frequency is related to the temperature due to the thermal expansion, which can be written as [25]

$$
\omega_{\mathrm{p}}=\omega_{\mathrm{p} 0} \times \exp \left(-\frac{\mathrm{T}-\mathrm{T}_{0}}{2} \times \alpha_{\mathrm{v}}\left(\mathrm{T}_{0}\right)\right)
$$

where $\mathrm{T}_{0}$ is the room temperature $\left(25^{\circ} \mathrm{C}\right), \omega_{\mathrm{p} 0}$ is the plasma frequency at $\mathrm{T}_{0}, \alpha_{\mathrm{v}}$ is the thermal volume expansion coefficient of metal. $\mathrm{T}$ is the real-time temperature, and our initial setting was $25^{\circ} \mathrm{C}$. In addition, we set two ways to make sure the outcome of a convergence test. Firstly a perfect matching layer (PML) with $1 \mu \mathrm{m}$ thickness is added to the outer computational region surrounding the analyte. Secondly the scattering boundary conditions at the outer boundary of PML are set. The meshing is a vital parameter to precisely investigate the simulated mode profile, and Fig. 1(b) shows our proposed sensor structure in the meshing map. The whole section of our proposed structure is divided into many triangular domains. The maximum triangular sizes in each area are $0.05 \mu \mathrm{m}$ (silicon core), $0.06 \mu \mathrm{m}$ (fused silica) cladding, $0.03 \mu \mathrm{m}$ (Au coating film), $0.3 \mu \mathrm{m}$ (analyte), and 2 $\mu \mathrm{m}$ (PML), respectively. The proposed sensor mesh consists of 125380 domain elements, 5488 boundary elements, and the total number of mesh elements of 862081 . Higher number mesh elements are better for the numerical simulation, which indicates the computational area is divided into the small region to get the result more accurate.

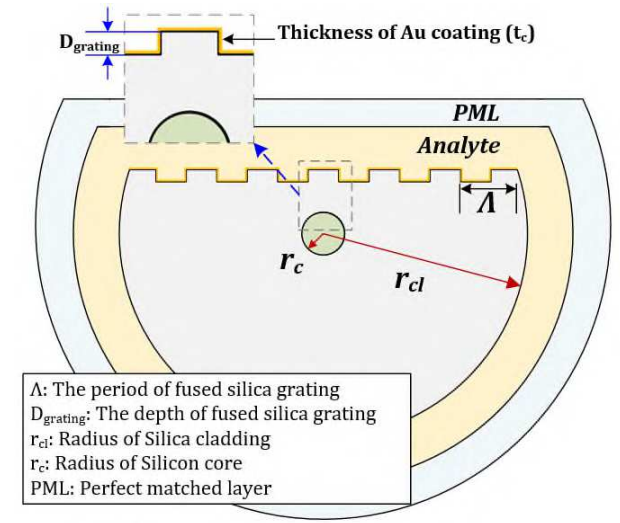

(a)

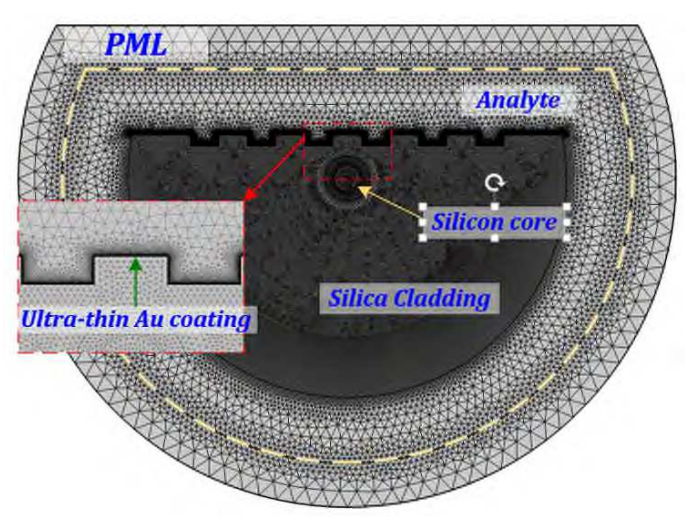

(b)

Fig. 1 (a) Cross-section of the proposed silicon core fiber-based sensor, (b) structure of the finite element in COMSOL Multiphysics.

The fabrication process of the proposed fiber sensor is shown in Fig.2. First, we need to prepare a silicon core and fused silica cladding fiber. Up to now, there are two fabrication methods for silicon core fiber including the research team fabricated semiconductor material-based core fiber by using the chemical vapor deposition method (CVD) in 2006 [26] and Ballato et al. fabricated the first silicon core 
fiber by using a high-speed and high-volume-fiber drawn technique which is called the molten core (MC) method in 2008 [27]. So far, the applications of SCF are already becoming more and more popular and useful, such as nonlinear optics effect [28] and in-line Schottky photodetectors [29] etc. In the second step, the D-shaped side polishing can be achieved using a micrometer-level metal V-shaped groove [30] and combining a grinding wheel with abrasive paper [31] in which the depth of D shaped is taken with $0.5 \mu \mathrm{m}$ above the core, which the mentioned methods could achieve. The third process $\mathrm{s}$ the fused silica to be etched periodically. In our simulation, the original design of the grating period $(\Lambda)$ and depth of grating $\left(D_{G}\right)$ are $1.3 \mu \mathrm{m}$ and $0.25 \mu \mathrm{m}$, respectively. So far, there are many methods and techniques to fabricate the fused silica-based grating period with around $1-\mu \mathrm{m}$ and to be lower than $100 \mathrm{~nm}$ surface quality by using the dry etching and laser-assisted etching [32]. In 2007, the authors demonstrated the dry etching technique to achieve the fused silica etching with period $0.89 \mu \mathrm{m}$ and depth $2 \mu \mathrm{m}$ [33]. The final process is to achieve the ultra-thin gold film coating. In our article, the proposed fiber sensor achieved only $2 \mathrm{~nm}$ ultra-thin Au film coating. Although it was very challenging to fabricate a metal thinfilm of only $2 \mathrm{~nm}$ thick, the low-pressure chemical vapor deposition (LPCVD) method is still used technique [34].

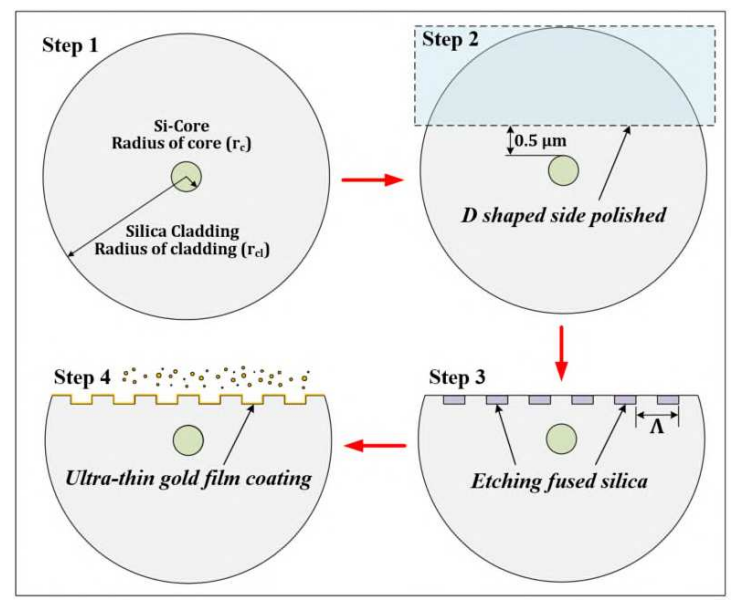

Fig. 2 Steps in the fabrication process. Step 1: Prepare one silicon core fiber. Step 2: D-shaped side polished on silicon core fiber. Step 3: Etched the fused silica cladding. Step 4: Ultra-thin Au coating on fused silica grating.
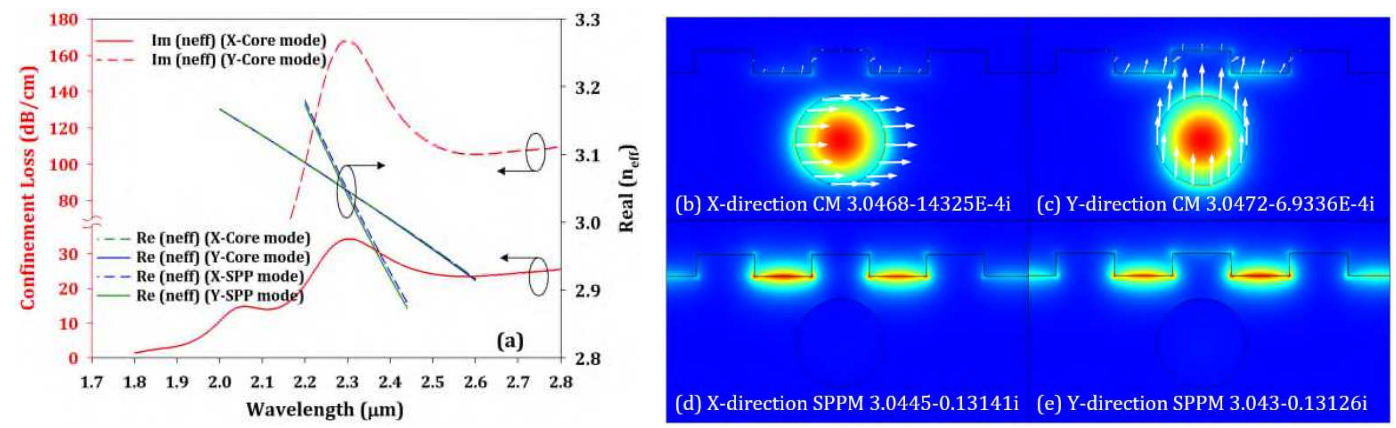

Fig. 3 (a) Dispersion relationship and confinement losses of the core mode and SPPs mode for an analyte refractive index of Ethanol. Calculated electric field distributions and effective refractive indices of (b) X-polarization direction core mode, (b) Y-polarization direction core mode, (c) X-polarization direction SPP mode, and (d) Y-polarization 
direction SPP mode at the 2.3- $\mu \mathrm{m}$ operating wavelength. (The white arrows represent the direction of the electric field.)

\section{Results and Discussion}

Theoretically, the resonance coupling between core modes and SPP modes can be occurred if the fundamental part of effective $\operatorname{RIs}\left[\operatorname{Re}\left(\mathrm{n}_{\text {eff }}\right)\right]$ is matched. In addition, the resonance is also characterized by a prominent peak of the core mode loss spectrum, which indicates the most significant energy transfer from the core mode to the SPP mode. Fig. 3(a) shows the $n_{\text {eff }}$ of the core mode and the surface plasmon polariton (SPP) mode with X- and Y-polarization direction when the analyte is Ethanol $\left(\mathrm{C}_{2} \mathrm{H}_{5} \mathrm{OH}\right)$. The confinement loss can be calculated from the imaginary part of the $n_{\text {eff }}\left[\operatorname{Im}\left(n_{\text {eff }}\right)\right]$ by using Eq. (5) [35]

$$
\alpha(d B / c m)=8.686 \times \frac{2 \pi \cdot \operatorname{Im}\left(n_{e f f}\right)}{\lambda} \times 10^{4}
$$

$\lambda$ is the free-space wavelength of incident light in $\mu \mathrm{m}$. The confinement loss curve is shown in Fig. 3(a) with red solid and dash lines. The resonance peaks of $\mathrm{X}$ - and Y-polarization direction are located at 2301.6 and $2298.6 \mathrm{~nm}$, respectively, where the fundamental part of the $\mathrm{n}_{\text {eff }}$ of the core modes and that of the SPP modes in corresponded polarization direction are matched. The peaks are the excited resonance wavelength due to the energy to be transferred into the SPP mode from the core mode. The electric field distributions of the modes with $2.3 \mu$ m operating wavelength are shown in Fig. 2(b)-(e). In Fig. 2(b) and (c), the white arrows represent the direction of the electric field because the arrow direction of Ypolarization points to the sensing medium directly and the confinement loss of Y-polarization is more significant than that of X-polarization.

However, the difference of confinement loss between X-and Y-polarization in our proposed design was still acceptable for sensing application. At the resonance wavelength of $2.3 \mu \mathrm{m}$, the core mode and SPP mode are mixed, which implies that a portion of core mode energy is penetrated in the SPP mode. When the refractive index of analyte $\left(n_{a}\right)$ is varied, the $\operatorname{Re}\left(n_{\text {eff }}\right)$ of core mode and SPP mode would also is varied to cause the shift of the resonance wavelength. According to the phenomenon, the $\mathrm{n}_{\mathrm{a}}$ variation can be detected by measuring both the $\mathrm{X}$ - and Y-polarization resonance peak shifts.

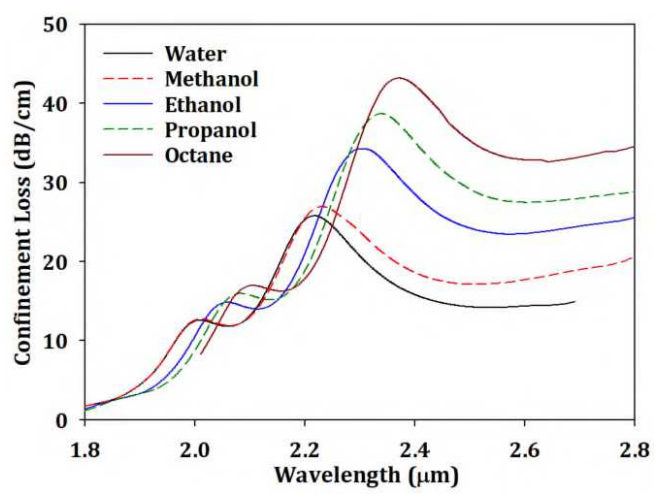

(a)

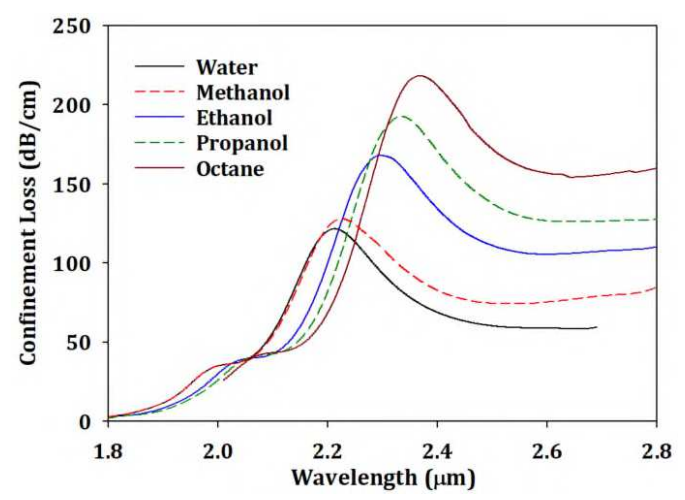

(b)

Fig. 4 The confinement loss versus the wavelength with different analytes for the proposed sensor in (a) Xpolarization (b) Y-polarization. 
Figure 4 represents the confinement loss versus the wavelength in $\mathrm{X}$ - and Y-polarization directions of the proposed sensor with different analytes. To confirm the theoretical simulation results close to the reality, five different liquid models are used for the refractive index sensing simulation including the water (Hale \& Querry,1973) [36], Methanol, Ethanol, Propanol and Octane (Myers et al., 2018) [37]. From the loss curve of X-polarization direction in Fig. 4(a), we can see that the peak losses are 25.78 $\mathrm{dB} / \mathrm{cm}, 26.95 \mathrm{~dB} / \mathrm{cm}, 34.25 \mathrm{~dB} / \mathrm{cm}, 38.69 \mathrm{~dB} / \mathrm{cm}, 43.18 \mathrm{~dB} / \mathrm{cm}$ with different analyte $\mathrm{n}_{\mathrm{a}}=$ water

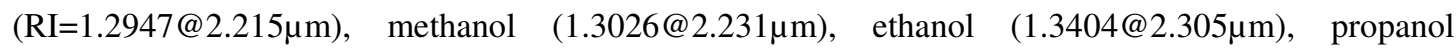

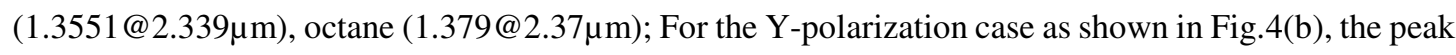
losses are $121.61 \mathrm{~dB} / \mathrm{cm}, 127.71 \mathrm{~dB} / \mathrm{cm}, 167.85 \mathrm{~dB} / \mathrm{cm}, 192.48 \mathrm{~dB} / \mathrm{cm}, 218.26 \mathrm{~dB} / \mathrm{cm}$ with different analytes $\mathrm{n}_{\mathrm{a}}=$ water $(\mathrm{RI}=1.2954 @ 2.207 \mu \mathrm{m})$, methanol $(1.3028 @ 2.221 \mu \mathrm{m})$, ethanol $(1.3431 @ 2.299 \mu \mathrm{m})$,

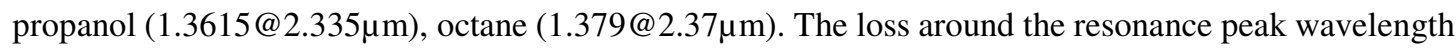
of the Y-polarization direction is about 4.73 to 5.05 times higher than that of X-polarization, which still could be acceptable for sensing applications. According to the results, the relationships of $n_{a}$ between resonance peak of the $\mathrm{X}$ - and $\mathrm{Y}$-polarization can be written as

$$
\left\{\begin{array}{l}
\lambda_{x}(\mu m)=1.8479 \cdot n_{a}-0.1771 \\
\lambda_{y}(\mu m)=1.9483 \cdot n_{a}-0.3170
\end{array}\left(1.28 \leq n_{a} \leq 1.38\right)\right.
$$

where $\lambda_{\mathrm{x}}$ and $\lambda_{\mathrm{y}}$ are the resonance peak of the $\mathrm{X}$ - and Y-polarization direction, respectively. Sensitivity is also a vital issue with measuring sensor's performance. It can be calculated by using the following formula. [13]

$$
S_{\lambda}(n m / R I U)=\Delta \lambda_{\text {peak }} / \Delta n_{a}
$$

where $\Delta \lambda_{\text {peak }}$ is the wavelength peak shift, and $\Delta \mathrm{n}_{\mathrm{a}}$ is the variation of the analyte's refractive index. In the proposed fiber sensor, the spectral sensitivities are 1838.7 and $1949.8 \mathrm{~nm} / \mathrm{RIU}$ of $\mathrm{X}$ - and Ypolarization direction. The relation gives the resolution of the proposed sensor. [13]

$$
R_{n}(R I U)=\Delta \mathrm{n}_{a} \times^{\Delta \lambda_{\min }} / \Delta \lambda_{\text {peak }}
$$

where $\Delta \mathrm{n}_{\mathrm{a}}$ is the variation in the RI of the analyte, $\Delta \lambda_{\text {min }}$ is the minimum spectral resolution, and $\Delta \lambda_{\text {peak }}$ is the resonance peak shift. As we take the $\Delta \lambda_{\min }$ of $0.1 \mathrm{~nm}$, the calculated resolution of the proposed in $\mathrm{X}$ - and Y-polarization direction are $5.3935 \times 10^{-5}$ and $5.1718 \times 10^{-5} \mathrm{RIU}$, respectively, which can be employed in the capability of the proposed sensor for detecting a slight change in RI of the analyte. 


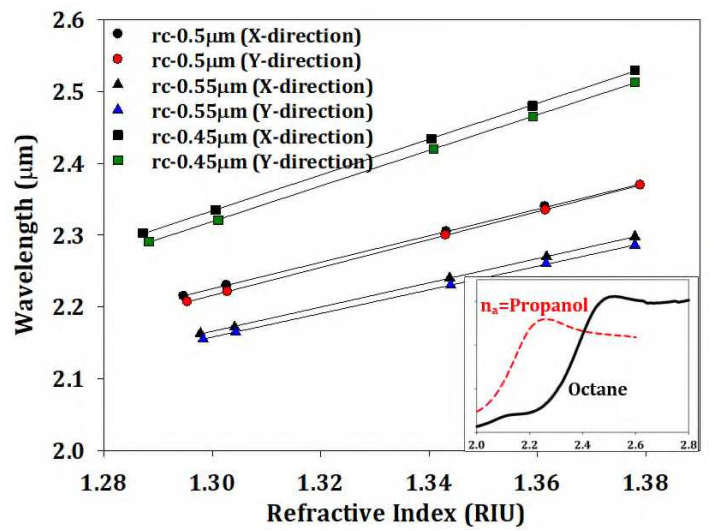

Fig. 5 The linear resonance wavelength shift versus refractive index for various analytes and different polarization directions. Inset: The loss spectrum of Y-polarization direction with $0.45-r_{c}$ and $n_{a}$ in Propanol and Octane.

Fig. 5 shows the resonance wavelength shift versus refractive index with different materials of analytes and $r_{c}$. We can see that as $r_{c}$ is decreased to $0.45 \mu \mathrm{m}$, the sensitivity would be increased up to $2.5 \mu \mathrm{m} / \mathrm{RIU}$. However, the smaller $r_{c}$ has a lower guiding ability which means more energy to be leaked. As shown in the inset of Fig. 5, the loss spectrum with $r_{c}$ of $0.45 \mu \mathrm{m}$ becomes worse when the $n_{a}$ is increased up to around $1.36(>21 \mathrm{~nm})$. The worse shape of the loss spectrum would cause the misjudgment during detection.

By referring to our previous research results, the thickness of coating film $(2 \mathrm{~nm})$ and D-shaped depth $(0.5 \mu \mathrm{m})$ [14], the $\Lambda$ of $1.3 \mu \mathrm{m}$ and $\mathrm{D}_{\mathrm{G}}$ of $0.25 \mu \mathrm{m}$ are designed in this part. In addition, in our simulation records, there is not noticeable difference when the cladding radius of fused silica is increased up to 62.5 $\mu \mathrm{m}$. Therefore, the $\mathrm{r}_{\mathrm{cl}}$ of $5 \mu \mathrm{m}$ is set for reducing the simulation cycles.
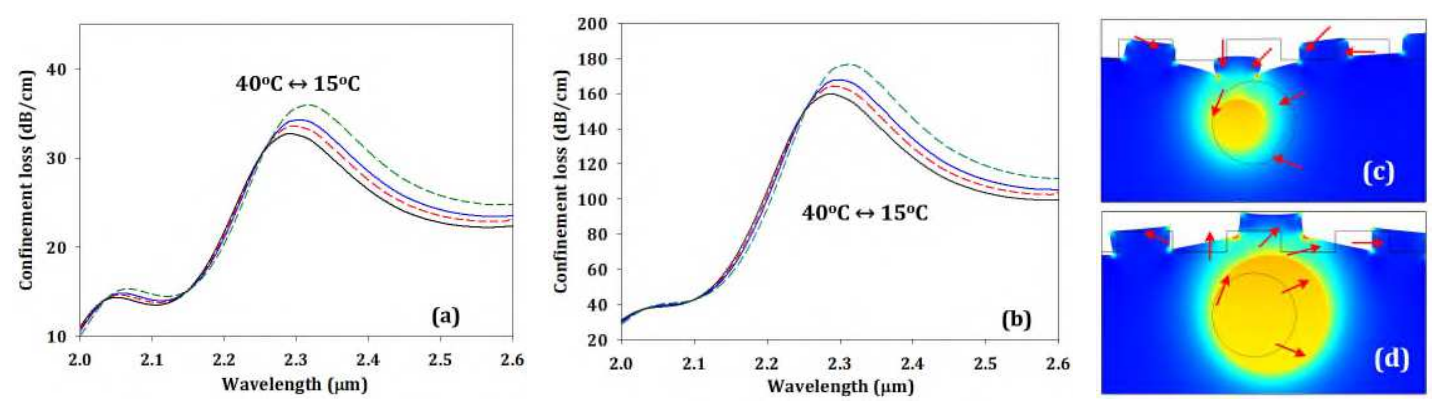

Fig. 6 (a) The X- and (b) Y-polarized confinement loss versus the wavelength for Ethanol analyte in different temperatures. The distribution of von Mises stress when the temperature is shifted toward (c) lower temperature and (d) higher temperature. (The red arrows represent the direction of von Mises stress.)

Fig. 6 (a) and (b) show the proposed fiber sensor's loss spectrum with different temperatures in X-and Y-polarized directions for Ethanol analyte $\left(\mathrm{n}_{\mathrm{a}}\right)$. The simulation results show that the resonant wavelength is shifted toward a shorter wavelength and the peaking loss is decreased as the temperature increases. In $\mathrm{X}$-polarized cased, when the temperatures is varied from $15{ }^{\circ} \mathrm{C}$ and $35^{\circ} \mathrm{C}$, the peaking losses at resonant 
wavelengths of $2.305,2.3182$, and $2.2846 \mu \mathrm{m}$ are $34.25,32.76$, and $35.97 \mathrm{~dB} / \mathrm{cm}$, respectively. The main factor to cause the wavelength shift and variation of peaking loss is the TOC of each material, in which a temperature variation is usually accompanied by an appreciable modification of the refractive index $n$ due to the TOC. Here, the TOC of Ethanol is $-3.94 \times 10^{-4} /{ }^{\circ} \mathrm{C}[20]$. For $\mathrm{Au}$ and fused silica, it can be respectively calculated by using Eq. (2) and (4) and TOC of Si can be obtained from ref. [38]. In addition, the temperature also affects the volume because the structure will be expanded or shrinked as the temperature is varied. The linear thermal-expansion coefficients of silicon, fused silica, and gold are $2.6 \times 10^{-6}, 0.4 \times 10^{-6}$, and $14 \times 10^{-6}$, respectively. The thermal expansion of the analyte can be neglected because it is a liquid in our proposed application. The Fig. 6 (c) and (d) show the distribution of von Mises stress for the temperature to be increased from $25^{\circ} \mathrm{C}$ to $35^{\circ} \mathrm{C}$ and is decreased from $25^{\circ} \mathrm{C}$ to $15^{\circ} \mathrm{C}$, respectively. The von Mises stress at the central point of silicon core is $2.25 \times 10^{6} \mathrm{~N} / \mathrm{m}^{2}$. As the temperature sensitivity is a critical parameter of a temperature sensor, it can be given by [20]

$$
S_{T}\left(n m /{ }^{\circ} \mathrm{C}\right)={ }^{\Delta \lambda_{\text {peak }}} / \Delta T
$$

where $\Delta \lambda_{\text {peak }}$ is the resonant wavelength shift and $\Delta \mathrm{T}$ is the temperature variation. For the above given parameters, as the temperature is varied from 15 to $40{ }^{\circ} \mathrm{C}$, the sensitivities in $\mathrm{X}$ - and Y-polarization direction are 1.601 and $1.622 \mathrm{~nm} /{ }^{\circ} \mathrm{C}$, respectively. Fig. 7 shows the $S_{\mathrm{T}}$ distribution when the $\Lambda$ and $\mathrm{D}_{\mathrm{G}}$ are changed from 1.1 to $1.5 \mu \mathrm{m}$ and 150 to $350 \mathrm{~nm}$, respectively. From this figure, we can see that the period of $1.3 \mu \mathrm{m}$ and depth of $250 \mathrm{~nm}$ for the grating has the best performance in $\mathrm{S}_{\mathrm{T}}$. Both of X-and $\mathrm{Y}$ polarization directions of $\mathrm{S}_{\mathrm{T}}$ values can reach up to $1.6 \mathrm{~nm} /{ }^{\circ} \mathrm{C}$. It is worth mentioning that the sensitivity is higher than those of most previous publications for sensing the Ethanol analyte.

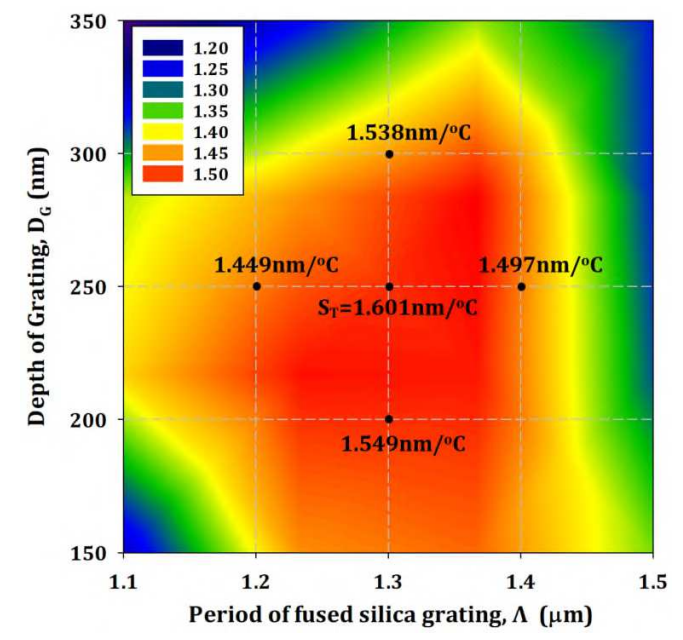

(a)

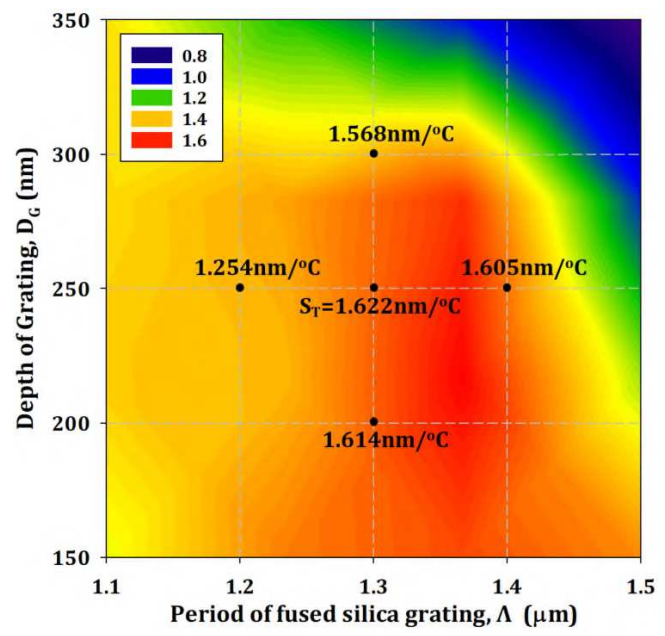

(b)

Fig. 7 The distribution of temperature sensitivity in Ethanol analyte with different values of $\Lambda$ and $D_{G}$;(a) $X$ polarization, (b) Y-polarization.

In order to confirm the temperature sensing performance, both the methanol and propanol liquids with the TOC of $4.3 \times 10^{-4}$ and $4.0 \times 10^{-4} /{ }^{\circ} \mathrm{C}$ [39] respectively are tested. Fig. 8 (a) and (b) illustrate the 
temperature sensing performance in polynomial fitting curves with the different polarization directions and analytes in the temperature range from $15^{\circ} \mathrm{C}$ to $40{ }^{\circ} \mathrm{C}$. The R-squared of the fitting curve is around 0.994. The $\mathrm{S}_{\mathrm{T}}$ of methanol in both $\mathrm{X}$ - and $\mathrm{Y}$-polarization are 1.616 and $1.64 \mathrm{~nm} /{ }^{\circ} \mathrm{C}$, and for the propanol the $S_{\mathrm{T}}$ values are 1.608 and $1.628 \mathrm{~nm} /{ }^{\circ} \mathrm{C}$, respectively. Thus the higher the TOC, the higher the $\mathrm{S}_{\mathrm{T}}$ for a testing liquid. It needs to mention is that there are overlap sections about $5 \mathrm{~nm}$ wide in the lower temperature of ethanol and in the higher temperature of propanol. However, the temperature difference in this section is more than $18^{\circ} \mathrm{C}$ for improving the misjudgment.

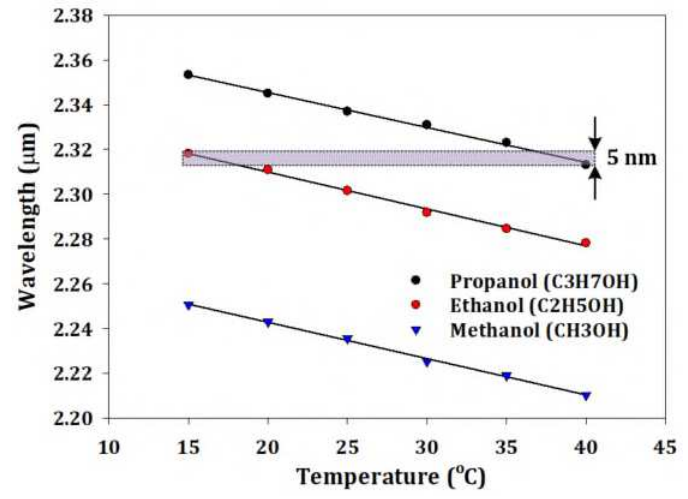

(a)

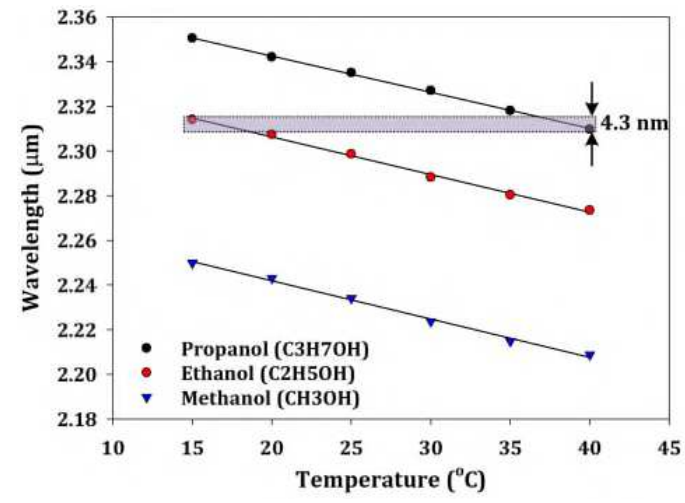

(b)

Fig. 8 The linear regression of the resonance wavelength with the different temperatures and (a) X-polarization, (b) Y-polarization in Propanol, Ethanol, and Methanol.

According to the results, the relationship between temperature and resonant wavelength in the different analytes and polarization directions could be written as

$$
\begin{aligned}
& \left\{\begin{array}{l}
\lambda_{x-\text { Propanol }}=-1.5600 \cdot 10^{-3} \cdot T+2.3766 \\
\lambda_{x-\text { Ethanol }}=-1.6491 \cdot 10^{-3} \cdot T+2.3429 \\
\lambda_{x-\text { Methanol }}=-1.6228 \cdot 10^{-3} \cdot T+2.2753
\end{array}\right. \\
& \left\{\begin{array}{l}
\lambda_{y-\text { Propanol }}=-1.6200 \cdot 10^{-3} \cdot T+2.3749 \\
\lambda_{y-\text { Ethanol }}=-1.6840 \cdot 10^{-3} \cdot T+2.3399 \\
\lambda_{y-\text { Methanol }}=-1.7143 \cdot 10^{-3} \cdot T+2.2761
\end{array}\right.
\end{aligned}
$$

The $\mathrm{T}$ is the environmental temperature in the range from $15^{\circ} \mathrm{C}$ to $40^{\circ} \mathrm{C}$ for the most common temperature in interior space in the world. The resolution of temperature measurement is also an important performance when this sensor detected the temperature tiny variation, and it can be expressed as

$$
R_{T}\left({ }^{\circ} \mathrm{C}\right)=\Delta T \times \Delta \lambda_{\min } / \Delta \lambda_{\text {peak }}
$$

where $\Delta \mathrm{T}$ is the temperature difference, and $\Delta \lambda_{\min }$ and $\Delta \lambda_{\text {peak }}$ are the same as those of Eq. (8). By using $\Delta \lambda_{\min }=0.1 \mathrm{~nm}$, the resolution was around $0.06^{\circ} \mathrm{C}$ in three different liquids. For neglecting the TOC and the ethanol analyte, Eq. (6), (10), and (11) are combined to obtain an equation for theoretically calculating both the RI and temperature simultaneously. It can be derived as

$$
\left[\begin{array}{l}
\Delta \lambda_{x} \\
\Delta \lambda_{y}
\end{array}\right]=\left[\begin{array}{ll}
\eta_{n x} & \eta_{T x} \\
\eta_{n y} & \eta_{T y}
\end{array}\right] \cdot\left[\begin{array}{l}
\Delta n \\
\Delta T
\end{array}\right]
$$

where $\Delta \mathrm{n}$ is the variation of the RI and $\Delta \mathrm{T}$ is the variation of the temperature, and the $\eta_{\mathrm{nx}}, \eta_{\mathrm{Tx}}, \eta_{\mathrm{ny}}$ and 
$\eta_{\mathrm{Ty}}$ are the sensitivity both of refractive index and temperature in $\mathrm{X}$ - and Y-polarization directions, respectively. Meanwhile, the theoretical wavelength shift caused by the variation of RI or temperature can be calculated by using Eq. (13). For the given values both of RI and temperature sensitivities, inverse matrices of Eq. (13) can be derived as

$$
\left[\begin{array}{l}
\Delta n \\
\Delta T
\end{array}\right]=\left[\begin{array}{cc}
-16.6604 & 16.3151 \\
19275.22 & 18281.93
\end{array}\right] \cdot\left[\begin{array}{l}
\Delta \lambda_{x} \\
\Delta \lambda_{y}
\end{array}\right]
$$

For relating to the issue of TOC compensation, Y. Zhang had already discussed and mentioned in [40]. There are two advantages of using our proposed fiber sensor. Firstly, from measuring two resonant peak wavelengths in the different polarization directions, the temperature and unknown liquid by referring to Fig. 8 the unknown liquid can be confirmed. Secondly the temperature is varied to obtain the fitting curve of resonant wavelengths in different temperatures for calculating the unknown TOC. Finally, the performance comparison between the proposed fiber sensor and the previously reported literatures is indicated in Table I.

Table I. Comparative Simultaneous Refractive Index and Temperature Sensing Performance Study with Existing Sensor

\begin{tabular}{|c|c|c|c|c|c|}
\hline $\begin{array}{l}\text { Refs. } \\
\text { (Year) }\end{array}$ & Sensor Type & $\begin{array}{l}\text { Refractive Index } \\
\text { Sensitivity } \\
\text { (RIU/nm) }\end{array}$ & $\begin{array}{l}\text { Refractive Index } \\
\text { Sensing Range } \\
\text { (RIU) }\end{array}$ & $\begin{array}{l}\text { Temperature } \\
\text { Sensitivity } \\
\left(\mathrm{nm} /{ }^{\circ} \mathrm{C}\right) \\
\end{array}$ & $\begin{array}{l}\text { Temperature } \\
\text { Sensing Range } \\
\left({ }^{\circ} \mathrm{C}\right) \\
\end{array}$ \\
\hline $\begin{array}{c}{[40]} \\
(2020)\end{array}$ & Hybrid Fiber Interferometer & 331.71 & $1.333-1.404$ & 1.053 & $30-70$ \\
\hline $\begin{array}{c}{[41]} \\
(2021)\end{array}$ & $\begin{array}{l}\text { Fiber surface waveguide/ } \\
\text { Fiber Bragg grating }\end{array}$ & 10.3 & $1.33-1.45$ & 0.01 & $20-80$ \\
\hline $\begin{array}{c}{[42]} \\
(2020)\end{array}$ & $\begin{array}{l}\text { Folded-tapered } \\
\text { multimode-no-core fiber }\end{array}$ & 1191.5 & $1.3405-1.3497$ & 0.065 & $20-90$ \\
\hline $\begin{array}{c}{[19]} \\
(2020)\end{array}$ & $\begin{array}{l}\text { Surface plasmon resonance with } \\
\text { multimode interference fiber sensor }\end{array}$ & 2061.6 & $1.333-1.383$ & 0.038 & $25-60$ \\
\hline $\begin{array}{c}{[43]} \\
(2021)\end{array}$ & $\begin{array}{l}\text { Surface plasmon resonance with } \\
\text { liquid-filled D-shaped PCF }\end{array}$ & 3940 & $1.35-1.4$ & 1.075 & $20-60$ \\
\hline $\begin{array}{c}{[18]} \\
\text { (2017) } \\
\text { Our past work }\end{array}$ & $\begin{array}{l}\text { Fiber Bragg grating/ } \\
\text { Long period fiber grating }\end{array}$ & 36.808 & $1.33-1.4$ & 0.3472 & $30-70$ \\
\hline This work & $\begin{array}{l}\text { Surface plasmon resonance with } \\
\text { fused silica grating }\end{array}$ & 1838 & $1.28-1.38$ & $>1.6$ & $15-40$ \\
\hline
\end{tabular}

\section{Conclusion}

An SPR fiber sensor based on an SCF and fused silica grating design is proposed in this paper. The sensitivity of RI of liquids is firstly analyzed in the index range between 1.28 to 1.38 . For the ethanol, the index sensitivities are 1838.7 and $1949.8 \mathrm{~nm} / \mathrm{RIU}$ in two different polarizations respectively. Secondly, the temperature measurement is theoretically calculated to analyze the thermal influence on the performance of our proposed fiber sensor. Considering the thermal expansion of structure and the TOC of the analyte, the temperature sensitivity of $1.6 \mathrm{~nm} /{ }^{\circ} \mathrm{C}$ can be obtained. In addition, we derive a relationship equation between the resonant wavelength peak shift, temperature, and RI variation and to investigate the sensor performance. It can provide a reference for the implementation and application of SCF-based SPR sensors in the intelligent sensing systems.

Acknowledgment This work was supported by the Ministry of Science and Technology in Taiwan 
Statements and Declarations The funding are all included in the section acknowledgment, and

there is no any conflicts of interest.

\section{Reference}

[1] Addanki, S., Amiri, I.S., Yupapin, P.: Review of optical fibers-introduction and application in fiber lasers. Results Phys. 10, 743-750 (2018)

[2] Qian, Y., Zhao, Y., Lu, Q., Yang, Y.: Review of salinity measurement technology based on optical fiber sensor. Sens. Actuator B-Chem. 260, 86-105 (2018)

[3] Massaroni, C., Zaltieri, M., Lo Presti, D., Nicolo, A., Tosi, D., Schena, E.: Fiber Bragg grating sensors for cardiorespiratory monitoring: A Review. IEEE Sens. J. 21, 14069-14080 (2021)

[4] Xu, B., Huang, J. Ding, L., Cai, J.: Graphene oxide-functionalized long period fiber grating for ultrafast labelfree glucose biosensor. Mater. Sci. Eng. C 107, 110329 (2020)

[5] Zuo, G., Li, W., Yang, Z. Li, S., Qi, R., Huang, Y., Xia, Li.: Double phase matching in MZI with antiresonant effect for optical fiber sensor application. J. Light. Technol. 39, 660-666 (2021)

[6] Li, Z., Zhang, Y. X., Zhang, W. G., Kong, L. X., Yue, Y., Yan, T. Y.: Parallelized fiber Michelson interferometers with advanced curvature sensitivity plus abated temperature crosstalk. Opt. Lett. 45, 4996-4999 (2020)

[7] Cui, X. L., Zhang, H., Wang, D. N.: Parallel structured optical fiber in-line Fabry-Perot interferometers for high temperature sensing. Opt. Lett. 45, 726-729 (2020)

[8] Moan, E. R., Horne, R. A., Arpornthip, T., Luo, Z., Fallon, A. J., Berl, S. J., Sackett, C. A.: Quantum rotation sensing with dual Sagnac interferometers in an atom-optical waveguide. Phys. Rev. Lett. 124, 120403 (2020).

[9] Lian, X. Wu, Q., Farrell, G., Semenova, Y.: High-sensitivity temperature sensor based on anti-resonance in high-index polymer-coated optical fiber interferometers. Opt. Lett. 45, 5385-5388 (2020)

[10] Amendola, V., Pilot, R., Frasconi, M., Marago, O. M., Lati, M. A.: Surface plasmon resonance in gold nanoparticles: a review. J. Phys. Condens. Matter 29, 203002 (2017)

[11] Zhang, Y., Liao, C., Lin, C., Shao, Y., Wang, Y., Wang, Y.: Surface plasmon resonance refractive index sensor based on fiber-interface waveguide inscribed by femtosecond laser. Opt. Lett. 44, 2434-2437 (2019).

[12] Fan, Z.: Surface plasmon resonance refractive index sensor based on photonic crystal fiber covering nano-ring gold film. Opt. Fiber Technol. 50, 194-199 (2019)

[13] Liu, Q., Sun. J., Sun, Y., Ren, Z., Liu, C., Lv, J., Wang, F., Wang, L., Liu, W., Sun, T., Chu, P. K.: Surface plasmon resonance sensor based on photonic crystal fiber with indium tin oxide film. Opt. Mater. 102, 109800 (2020)

[14] Yu, Y. L., Liaw, S. K., Kishikawa, H., Goto, N.: D-shaped silicon core fiber-based surface plasmon-resonance refractive index sensor in $2 \mu \mathrm{m}$. Appl. Optics 59, 5539-5546 (2020)

[15] Han, Y., Gong, L., Meng, F., Chen, H., Wang, Y., Li, Z., Zhou, F., Yang, M., Guan, J., Yun, W., Guo, X., Wang, W.: Highly sensitive temperature sensor based on surface plasmon resonance in a liquid-filled hollow-core negative-curvature fiber. Optik 241, 166970 (2021)

[16] Jimenez Rioboo, R. J., Philipp, M., Ramos, M. A., Kruger, J. K.: Concentration and temperature dependence of the refractive index of ethanol-water mixtures: Influence of intermolecular interactions. Eur. Phys. J. E 30, 19$26(2009)$

[17] Ge, Y., Liu, Q., Chang, J., Zhang, J.: Optical fiber sensor for temperature measurement based on Silicon thermooptics effect. Optik, 124 6946-6949 (2013)

[18] Yu, Y. L., Hung, H. H., Liaw, S. K., Shih, M. H., Kishikawa, H., Goto.: Simultaneously two-parameter measurement using tilted fiber grating and long period fiber grating. Microw. Opt. Technol. Lett. 59, 1122-1125 (2017)

[19] Zhang, Y., Liu, M., Zhang, Y., Liu, Z., Yang, X., Zhang, J., Yang, J., Yuan, L.: Simultaneous measurement of temperature and refractive index based on a hybrid surface plasmon resonance multimode interference fiber sensor. Appl. Optics 59, 1225-1229 (2020)

[20] Osifeso, S., Chu, S., Prasad, A., Nakkeeran, K.: Surface plasmon resonance-based temperature sensor with outer surface metal coating on multi-core photonic crystal fiber. Surfaces 3, 337-351 (2020)

[21] Zhu, J., Li, N.: Novel high sensitivity SPR sensor based on surface plasmon resonance technology and IMI waveguide structure. Results Phys. 17, 103049 (2020)

[22] Salzberg, C. D., Villa, J. J.: Infrared refractive indexes of Silicon Germanium and modified Selenium glass. J. Opt. Soc. Am. 47, 244-246 (1957)

[23] Peng, Y., Hou, J., Huang, Z., Lu, Q.: Temperature sensor based on surface plasmon resonance within selectively coated photonic crystal fiber. Appl. Optics 51, 6361-6367 (2012)

[24] Johnson, P. B., Christy, R. W.: Optical constants of the noble metals', Phys. Rev. B 6, 4370-4379 (1972)

[25] Lin K., Lu, Y., Luo, Z., Zheng, R., Wang, P., Ming, H.: Numerical and experimental investigation of temperature effects on the surface plasmon resonance sensor. Chin. Opt. Lett. 7, 428-431 (2009)

[26] Sazio, P. J. A., Amezcua-Correa, A., Finlayson, C. E., Hayes, J. R., Scheidemantel, T. J., Baril, N. F., Jackson, B. R., Won, D. J., Zhang, F., Margine, E. R., Gopalan, V., Crespi, V. H., Badding, J. V.: Microstructured optical 
fibers as high-pressure microfluidic reactors. Science 311, 1583-1586 (2006)

[27] Ballato, J., Hawkins, T., Foy, P., Stolen, R., Kokuoz, B., Ellison, M., McMillen, C., Reppert, J., Rao, A. M., Daw, M., Sharma, S., Shori, R., Stafsudd, O., Rice, R. R., Powers, D. R.: Silicon optical fiber. Opt. Express 16, 18675-18683 (2008)

[28] Wu, D., Shen, L., Ren, H., Huang, M., Lacava, C., Campling, J., Sun, S., Hakins, T. W., Gibson, U. J., Petropoulos, Ballato, J., Peacock, A. C Peacock.: Four-wave mixing-based wavelength conversion and parametric amplification in submicron Silicon core fibers. IEEE J. Sel. Top. Quantum Electron 27, 4300111 (2021)

[29] Lu, W. C., Wu, C. H., Yeh, C. Y., Wu, C. H., Wang, C. L., Wang, L. A.: D-shaped Silicon-cored fibers as platform to build in-line Schottky photodetectors. IEEE Photonics Technol. Lett. 33, 317-320 (2021)

[30] Chen, Z. X., Wu, Z. J., Ming, Y., Zhang, X. J., Lu, Y. Q.: Hybrid plasmonic waveguide in a metal V-groove. AIP Adv. 4, 017103 (2014)

[31] Luo, W., Meng, J., Li, X., Xie, Q., Yi, D., Wang, Y., Hong, X.: Temperature effects on surface plasmon resonance sensor based on side-polished D-shaped photonic crystal fiber. Measurement 181, 109504 (2021)

[32] Kotz, F., Risch, P., Arnold, K., Sevim, S., Puigmarti-Luis, J., Quick, A., Thiel, M., Hrynevich, A., Dalton, P. D., Helmer, D., Rapp, B. E.: Fabrication of arbitrary three-dimensional suspended hollow microstructures in transparent fused silica glass. Nat. Commun. 10, 1439 (2019)

[33] Wang, B., Zhou, C., Wang, S., Feng, J.: Polarizing beam splitter of a deep-etched fused-silica grating. Opt. Lett. 32, 1299-1301 (2007)

[34] Luhmann, N., Hoj, D., Piller, M., Kahler, H., Chien, M. H., West, R. G., Andersen, U. L., Schmid, S.: Ultrathin $2 \mathrm{~nm}$ gold as ideal impedance matched absorber for infrared light. Nat. Commun. 11, 2161 (2020)

[35] Hassani, A., Skorobogatiy, M.: Design criteria for microstructured-optical-fiber-based surface-plasmonresonance sensors. J. Opt. Soc. Am. B 24, 1423-1429 (2007)

[36] Hale, G. M., Querry, M. R.: Optical constants of water in the 200-nm to 200- $\mu$ m wavelength region. Appl. Optics 12, 555-563 (1973)

[37] Myersm, T. L., Tonkyn, R. G., Danby, T. O., Taubman, M. S., Bernacki, B. E., Birnbaum, J. C., Sharpe, S. W., Johnson T. J.: Accurate measurement of the optical constants $\mathrm{n}$ and $\mathrm{k}$ for a series of 57 inorganic and organic liquids for optical modeling and detection. Appl. Spectrosc. 72, 535-550 (2018)

[38] Frey, B. J., Leviton, D. B., Madison, T. J.: Temperature-dependent refractive index of silicon and germanium. Proc. SPIE 6273, Optomechanical Technologies for Astronomy, 62732J (2006)

[39] Bauld, R., Choi, D. Y. W., Bazylewski, P., Divigalpitiya, R., Fanchini, G.: Thermo-optical characterization and thermal properties of graphene-polymer composites: a review. J. Mater. Chem. 6, 2901-2914 (2018)

[40] Hu, Y., Lin, Q., Yan, F., Xiao, L., Ni, L., Liang, W., Chen, L., Liu, G., Chen, Y., Luo, Y., Chen, Z.: Simultaneous measurement of the refractive index and temperature based on a hybrid fiber interferometer. IEEE Sens. J. 20, 13411-13417 (2020)

[41] Chen, Q., Wang, D. N., Gao, F.: Simultaneous refractive index and temperature sensing based on a fiber surface waveguide and fiber Bragg gratings. Opt. Lett. 46, 1209-1212 (2021)

[42] Wang, F., Pang, K., Ma, T., Wang, X., Liu, Y.: Folded-tapered multimode-no-core fiber sensor for simultaneous measurement of refractive index and temperature. Opt. Laser Technol. 130, 106333 (2020)

[43] Chen, A., Yu, Z., Dai, B., Li, Y.: Highly sensitive detection of refractive index and temperature based on liquidfilled D-shape PCF. IEEE Photonics Technol. Lett. 33, 529-532 (2021) 